Revue d'histoire de l'Amérique française

TH REYUE D.HISTOIRE DE L'AMÉRIQUE FRANÇAISE

TROFIMENKOFF, Susan Mann, Action française; French

Canadian Nationalism in the Twenties. University of Toronto

Press, Toronto et Buffalo, 1975. 156 p. \$10.95

\title{
Richard-A. Jones
}

Volume 30, numéro 1, juin 1976

URI : https://id.erudit.org/iderudit/303519ar

DOI : https://doi.org/10.7202/303519ar

Aller au sommaire du numéro

Éditeur(s)

Institut d'histoire de l'Amérique française

ISSN

0035-2357 (imprimé)

1492-1383 (numérique)

Découvrir la revue

Citer ce compte rendu

Jones, R.-A. (1976). Compte rendu de [TROFIMENKOFF, Susan Mann, Action française; French Canadian Nationalism in the Twenties. University of Toronto Press, Toronto et Buffalo, 1975. 156 p. \$10.95]. Revue d'histoire de l'Amérique française, 30(1), 121-123. https://doi.org/10.7202/303519ar d'utilisation que vous pouvez consulter en ligne.

https://apropos.erudit.org/fr/usagers/politique-dutilisation/ 
Trofimenkoff, Susan Mann, Action française; French Canadian Nationalism in the Twenties, University of Toronto Press, Toronto et Buffalo, 1975. 156 p. \$10.95.

L'auteur compte parmi plusieurs Canadiens d'origine anglaise qui se sont intéressés au Québec par le biais du nationalisme. Comme elle l'explique, les Québécois se sont fait connaître à l'extérieur de la province largement grâce à la diffusion du message nationaliste depuis au moins un siècle et demi. Non seulement le message était-il particulièrement vigoureux mais aussi les projets des nationalistes québécois ne pouvaient manquer de toucher le Canada anglais. L'anti-impérialisme, l'anti-conscriptionnisme, la dualité culturelle et linguistique, l'autonomisme, le séparatisme politique, tous ces thèmes supposaient et supposent des modifications du comportement de l'anglophone. Par contre, les Québécois qui se sont exprimés sur des questions économiques et sociales purement québécoises ont suscité relativement moins d'intérêt à l'extérieur.

Madame Trofimenkoff estime aussi que les historiens québécois contemporains, sans doute par réaction aux excès du passé, ont largement délaissé l'aspect nationaliste pour explorer des champs dits «nouveaux», tels l'économie, les classes sociales, le monde politique. Certes, cette diversification fut nécessaire, mais il ne faut pas non plus ignorer le message nationaliste. C'est dans cette optique que l'auteur nous offre une version remaniée de sa thèse de doctorat portant sur l'Action française de chez nous.

Ce court texte est de lecture fort agréable et l'historienne manifeste certainement des dons d'écrivain. Après avoir fait ressortir les principaux éléments du contexte du début du vingtième siècle, l'auteur examine les racines de l'Action française au Québec et en France. Dans le premier cas, elle s'attache à l'œuvre de Jules-Paul Tardivel, de Mgr Louis-Adolphe Pâquet et d'Henri Bourassa. D'autre part, elle soutient que l'Action française s'est contentée d'emprunter à la France ce qu'elle voulait: un appui pour la mission culturelle, intellectuelle et religieuse du Canada français ainsi qu'une «prestigieuse confirmation de la valeur du nationalisme».

Le lecteur peut prendre conscience aussi de l'attitude de L'Action française face à la langue, à l'industrialisation, à l'urbanisation et au monde politique mais, s'il connaît déjà les préoccupations et les attitudes des nationalistes de l'époque, ce sera du déjà vu. Plus intéressante pour lui sera la discussion des problèmes internes de la revue et du mouvement, des mé- 
sententes et des conflits entre certains des animateurs qui en ont certainement précipité le déclin. Les finances, par exemple, étaient généralement dans un état lamentable alors que les directeurs de la Ligue préféraient ne discuter que de théories.

Les gens de l'Action française comme les autres nationalistes vivent sous un ciel peuplé d'innombrables ennemis et le message inlassablement répété consiste à aguerrir les troupes pour qu'elles résistent aux assauts ininterrompus. Pour L'Action française, la situation est encore plus urgente: les ennemis ne sont plus à l'extérieur des remparts, ils se trouvent bel et bien dans la cité. La langue française est menacée par ses propres usagers, les francophones pour qui l'anglais est un symbole de prestige et de succès. Nos gouvernants sont complices de la malheureuse urbanisation et industrialisation de la province. Les politiciens, toujours à la poursuite de leurs propres ambitions égoïstes, divisent le peuple au lieu de l'unir.

Si L'Action française identifie et condamne les ennemis, ses solutions sont le plus souvent vagues et elle traverse allègrement les dilemmes suscités par les remèdes qu'elle propose. D'une part, elle souhaite un équilibre entre le monde industriel et celui de l'agriculture qui restaurerait la position suprême de cette dernière, mais d'autre part, elle se rend bien compte que pour survivre il faut se préoccuper du bien-être matériel. L'émigration des nôtres vers les États-Unis est un désastre national, mais la colonisation des régions éloignées est-elle un remède susceptible de la stopper? (De l'avis du journal Le Soleil, L'Action française avait une vue plutôt simpliste de la colonisation: "Passer sa vie dans les arbres en compagnie des maringouins»!). La survivance culturelle et l'urbanisation de la société canadiennefrançaise semblent incompatibes, mais le Québec est urbain à plus de $50 \%$ depuis 1921. Certaines solutions politiques, comme l'indépendance, sont à envisager, mais en général le monde politique suscite de la méfiance et les gens de l'Action française sont réticents à y participer.

L'influence de l'Action française est difficile à évaluer. Certes, plusieurs de ses luttes ont été vaines. En effet, le Québec a continué de s'urbaniser et de s'industrialiser et, comme le souligne l'auteur, les «sermons économiques [de L'Action française] semblent avoir eu peu d'effet sur le Québec contemporain.» Mais sur d'autres plans, ne faudrait-il pas atténuer ce constat d'échec? La situation de la langue française n'est plus du tout aujourd'hui celle qu'elle a été dans les années 1920. Certaines idées politiques, comme le séparatisme, ne sont plus limitées au seul camp des intellectuels. Et c'est aussi avec l'Action française que le nationalisme commence à rompre ses attaches traditionnelles avec le clergé (malgré le nombre élevé de prêtres qui ont participé au mouvement), et qu'il revêt un aspect plus québécois et moins canadien.

Cette monographie apporte beaucoup à nos connaissances du nationalisme québécois pour la période entre la première grande guerre et le début 
de la crise économique. Il ne reste qu'à déplorer les ravages de l'inflation: $\$ 10.95$ pour 120 pages de texte!

Université Laval

RICHARD-A. JONES 